\title{
Study of structure and quality of different silicon oxides using FTIR and Raman microscopy
}

\author{
C. Moore ${ }^{\mathrm{a}}$, T.S. Perova*a ${ }^{* a}$ B. Kennedy**b, K. Berwick ${ }^{\mathrm{c}}$, I.I. Shaganov ${ }^{\mathrm{d}}$, and R.A. Moore ${ }^{\mathrm{a}}$ \\ ${ }^{a}$ Dept.Electr.\& Electr. Eng., Trinity College, Ireland; ${ }^{b}$ Intel Ltd., Ireland; ${ }^{c}$ Dept. Electr. \& Commun. \\ Eng., DIT, Kevin Street, Ireland; ${ }^{\mathrm{d}}$ Vavilov State Optical Inst., St.Petersburg, Russia.
}

\begin{abstract}
In this work, $\mathrm{SiO}_{2}$ and fluorine and phosphorous doped $\mathrm{SiO}_{2}$ thin films are investigated using FTIR and Raman techniques. FTIR spectroscopy was performed at normal and oblique incidence of the probe beam in transmission and reflection modes. The effect of polarisation and angle of incidence of the probe beam is examined for the case of reflection mode. Infrared spectra taken from doped oxides show that the structure changes with the passage of time. Alternate methods to calculate the thickness of the doped film are also discussed. Infrared spectra of electron beam evaporated oxides give valuable information on their structure and water content. The porosity is calculated for these samples. Finally, micro-Raman spectroscopy is used to measure the fluorine content in a device structure.
\end{abstract}

\section{INTRODUCTION}

Investigation of the structure and the defects present within thin films formed on silicon is crucially important in microelectronics. Fourier Transform Infrared (FTIR) spectroscopy provides a direct probe of molecular and submolecular structures via the excitation of vibrational states in the molecules over a specific mid-IR range (400$5000 \mathrm{~cm}^{-1}$ ) [1-8]. Raman spectroscopy has been utilised recently to investigate stress and phase transformation in silicon structures [9-14]. The greatest advantages of both these techniques are its non-destructive character, the simplicity of the equipment set-up and the short time required for obtaining data, with essentially no sample preparation process required and no surface damage. The application of these powerful techniques allows information on the structure, stress, thickness, porosity, density, carrier concentration and several other important properties of thin films to be obtained. In this paper, a number of thin films are investigated; namely $\mathrm{SiO}_{2}$, fluorine doped $\mathrm{SiO}_{2}$ and phosphorus doped $\mathrm{SiO}_{2}$. Fluorine and phosphorus doped oxides were investigated since these are important materials in the microelectronics industry. In particular, fluorine doped $\mathrm{SiO}_{2}$ has a low dielectric constant which decreases parasitic capacitance. These films were deposited on silicon and aluminium substrates by thermal oxidation and electron beam evaporation. We also analysed a composition of $\mathrm{SiO}_{2}$ doped with fluorine within a FIB box in a technologically patterned wafer in order to determine the concentration of fluorine in some important areas along the devices structure of this FIB box.

\section{EXPERIMENTAL}

\subsection{Sample Preparation}

Fluorine doped $\mathrm{SiO}_{2}$ films were deposited using a parallel-plate electrode Plasma Enhanced Chemical Vapour Deposition (PECVD) reactor. The chamber was evacuated to a pressure of $5.3 \times 10^{-7} \mathrm{~Pa}$. The films were formed by adding $\mathrm{CF}_{4}$ (as the fluorine source) to $\mathrm{SiH}_{4} / \mathrm{N}_{2} \mathrm{O}$. Argon was used as the carrier gas. Prior to deposition, the silicon

*perovat@tcd.ie; phone 353 1608-3802; fax 3531 677-2442; http://www.tcd.ie; Department of Electronic \& Electrical Engineering, University of Dublin, Trinity College, Dublin 2, Ireland; barry.j.kennedy@intel.com; phone 3531606 7000; Intel Ireland Ltd., Collinstown Industrial Park, Lexlip, County Kildare, Ireland. 
substrate was dipped in HF to remove any native oxide. Two fluorine doped oxide samples with concentrations of 3.18 at. $\%$ and 5.13 at. $\%$ and one phosphorus doped sample with a concentration of 4.6 at $\% \%$ have been used in this study. Evaporated $\mathrm{SiO}_{2}$ films with different thicknesses were deposited using electron beam evaporation onto silicon substrates. They were prepared by the vacuum evaporation of vitreous quartz pieces in a bell jar evaporator from a heated tantalum crucible. A high vacuum $\left(\leq 1.3 \times 10^{-3} \mathrm{~Pa}\right)$ and a high deposition rate $\left(\geq 1.5 \mathrm{~nm} \mathrm{~s}^{-1}\right)$ were used to ensure that there would be no excess oxygen in the deposited films.

\subsection{FTIR measurements}

FTIR was performed at normal and oblique incidence of the probe beam in transmission and reflection modes. Transmission mode FTIR is possible only if the substrate is IR transparent and therefore cannot be employed to examine patterned wafers. Most devices are, however, multilayered and normally opaque to IR light. Infrared reflection-absorption spectroscopy (IRRAS) avoids this problem by examining the reflected light from a sample's surface $[8,15-17]$. IRRAS has the advantage of enhancing the absorption at the surface of a sample thus aiding the investigation of very thin films, which normally have weak absorption. Both IRRAS and oblique transmission techniques [5-8] also allow observation of the Longitudinal Optical (LO) phonons which cannot be detected otherwise. Also, the reflection-absorption measurements at two different angles allows one to measure the thickness of the layer by using the Fabry-Perot method.

Digilab FTS60A and FTS6000 FTIR spectrometers were used to carry out IR measurements. An IR spectrum of the original $\mathrm{Si}$ wafer was taken as the reference. The spectrum taken for the oxidised samples contained information on both the $\mathrm{SiO}_{2}$ layer and the $\mathrm{Si}$ substrate. By subtracting the $\mathrm{Si}$ reference spectrum from the sample spectra, information could be extracted regarding the $\mathrm{SiO}_{2}$ layer only.

Both FTIR spectrometers are equipped with Perkin-Elmer variable angle reflection-absorption attachments. All spectra measured with the IRRAS method were collected as single beam spectra. To improve the signal to noise ratio, 128 scans are recorded, co-added and then averaged. A single beam reflectance spectrum was taken from an aluminium mirror and then ratioed with the sample's single beam spectrum in order to obtain the reflectance spectrum.

\subsection{Raman measurements}

Raman spectra were registered in backscattering geometry using a Renishaw 1000 micro-Raman system equipped with a Leica microscope and an XYZ motorised positional stage. Using the 100x magnification objective in the microscope and an $\mathrm{Ar}^{+}$ion laser with a $514 \mathrm{~nm}$ excitation line allows Raman imaging of the surface with a spatial resolution of $\sim 0.7 \mu \mathrm{m}$. All spectra were recorded with a low laser power of $\sim 20 \mathrm{~mW}$. The auto-focus line-mapping facility of the Raman system has been employed in this study. This allows the collection of spectra at each point along the chosen line with a $0.1 \mu \mathrm{m}$ step and with automatic focusing of the laser spot onto the mapped area. 101 Raman spectra were collected along the chosen line $\left(\sim 10 \mu \mathrm{m}\right.$ in length) in a FIB box starting at the $\mathrm{CoSi}_{-} \mathrm{SiO}_{2}+\mathrm{P}$ interface. The acquisition time of 100s was used for all line-mapping sessions. 300s was required in order to register the Raman spectrum of the CoSi layer. For each line, the line-mapping experiment was performed at least four times. The results obtained in these four mapping session are similar.

\section{RESULTS AND DISCUSSION}

\subsection{Doped Oxides}

Typically, a few vibrational bands belonging to Si-O vibrations such as stretching vibrations at $\sim 1080 \mathrm{~cm}^{-1}$, Si-O bending vibrations at $\sim 800 \mathrm{~cm}^{-1}$ and rocking vibrations at $\sim 450 \mathrm{~cm}^{-1}$ will be observed in the infrared spectra of silicon dioxide [1-8]. As was shown in the past, the intensity of these bands can be used for oxide thickness determination.

If $\mathrm{SiO}_{2}$ is doped with fluorine, an additional peak appears in the spectrum centred at $945 \mathrm{~cm}^{-1}$ (see Fig. 1). The intensity of this band increases with dopant concentration while the $460 \mathrm{~cm}^{-1}$ band decreases in intensity and shifts to a slightly lower frequency. The positions and intensities of the $800 \mathrm{~cm}^{-1}$ and $1080 \mathrm{~cm}^{-1}$ bands are not affected appreciably. For 
silicon dioxide doped with phosphorus, an additional vibrational band belonging to P-O appears at $\sim 1300 \mathrm{~cm}^{-1}$ (see Fig. 2) [18].

Measurements were repeated for the doped oxide samples six months after initial deposition. It was found that the intensity of the Si-O-Si bond vibration was significantly reduced when compared to the as-grown oxide. The $460 \mathrm{~cm}^{-1}$ and $1080 \mathrm{~cm}^{-1}$ bands are reduced by more than half their original intensity for a 5.13 at. \% fluorine doped oxide, while the $800 \mathrm{~cm}^{-1}$ mode remains unchanged. This mode can, therefore, be reliably used for film thickness evaluation, unlike the $460 \mathrm{~cm}^{-1}$ and $1080 \mathrm{~cm}^{-1}$ bands. Fig. 2 shows the IR spectrum of a phosphorus doped oxide over time. The structure of the phosphorus doped oxide has changed, but not as much as for the fluorine sample. The $810 \mathrm{~cm}^{-1}$ band is unaltered, as in the case for the fluorine doped sample. It is presumed that this happened because the doped $\mathrm{SiO}_{2}$ was not annealed enough after the deposition. Due to this, the fluorine and phosphorus diffuse through the bulk oxide to the surface where they create haze particles in the same manner as it was observed in Refs. $[19,20]$.

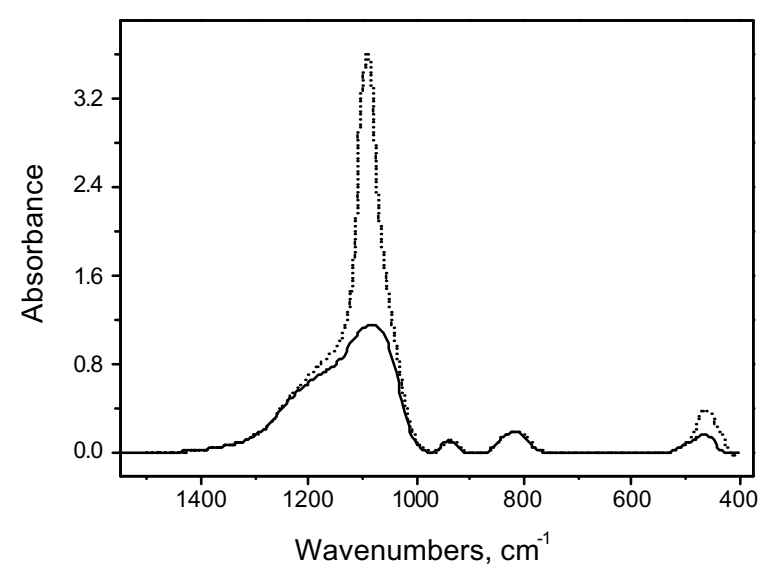

Figure 1. FTIR spectra of fluorine doped (5.13 at. $\%) \mathrm{SiO}_{2}$, measured after the deposition (dotted line) and 6 month later (solid line).

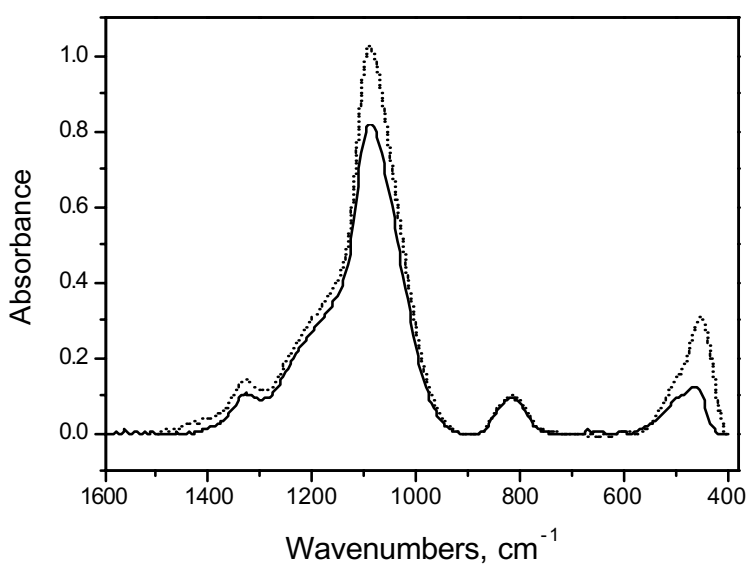

Figure 2. FTIR spectra of phosphorous doped (4.6 at \%) $\mathrm{SiO}_{2}$, measured after the deposition (dotted line) and 6 month later (solid line).

\subsection{Comparison of Thermal and Evaporated Oxides}

Fig. 3 shows the absorbance spectra for a $1 \mu \mathrm{m} \mathrm{SiO}_{2}$ film on silicon deposited by thermal oxidation and evaporation. The spectrum of the evaporated oxide shows a pronounced difference in the intensity of the $1080 \mathrm{~cm}^{-1}$ and $800 \mathrm{~cm}^{-1}$ bands when compared to the thermally grown oxide (Fig. $3 a$ ). This would indicate that the structure of the oxide is different for each case. In addition, the spectrum of the evaporated film shows the presence of a new band at $935 \mathrm{~cm}^{-1}$. This band is attributed to the vibration of $\mathrm{Si}-\mathrm{OH}$ groups, indicating that water has reacted with the $\mathrm{SiO}_{2}$ to form $\mathrm{SiOH}$.

The presence of $\mathrm{O}-\mathrm{H}$ and $\mathrm{Si}-\mathrm{OH}$ groups will also affect the spectrum in the range $2500-4000 \mathrm{~cm}^{-1}$ (see Fig. $3 \mathrm{~b}$ ). An absorbance band in this range was also analysed. The intensity of this wide band increases for the evaporated case with a maximum at around $3400 \mathrm{~cm}^{-1}$ and is attributed to $\mathrm{O}-\mathrm{H}$ stretching vibrations. The intensity of this band is directly proportional to the water content in the oxide as well as to the film porosity [21]. The evaporated oxide has a higher water content than the thermally grown oxide, indicating that the evaporated oxide is more porous. The $\mathrm{OH}$ groups present in the pores are negative ions and are not neutral like $\mathrm{H}_{2} \mathrm{O}$. These ions will increase the refractive index and give larger thickness readings when measured with ellipsometry.

The porosity of dioxides can be evaluated using FTIR data in the region of the O-H stretching vibration. The method suggested in Ref. [21] is applicable for the calculation of the open porosity of thin dielectric films from infrared spectra and has therefore been used. The open porosity, identical to the relative content of incorporated moisture, is given, in this case, by the ratio of the total intensities (or absorption coefficients) at the maximum of the bands of the absorbed 
and liquid water in the region 3000-3600 $\mathrm{cm}^{-1}$. Taking into account the local field acting in both cases on the water molecule in accordance with Ref. [22], the porosity $V$ can be defined by the following equation:

$$
V=\frac{n_{f} \int K_{f}(v) q_{f}^{-2}(v) d v}{n_{w} \int K_{w}(v) q_{w}^{-2}(v) d v}
$$

where the subscripts $f$ and $w$ respectively denote "film" and liquid "water", $K(v)$ is Lambert-Bouger absorption coefficient in $\mathrm{cm}^{-1}$ and $n$ is the refractive index. Assuming that the shape of the vibrational bands does not change upon absorption and using the mean values of the local field factors, $\mathrm{q}_{\mathrm{f}}$ and $\mathrm{q}_{\mathrm{w}}$, in the Lorentz form (see [22] for details) we can obtain:

$$
V=\frac{K_{f \max } n_{f}\left(n_{w}^{2}+2\right)^{2}}{K_{w \max } n_{w}\left(n_{f}^{2}+2\right)^{2}} 100 \%
$$

The values of $K_{w \max }$ and $n_{w}$ were taken equal to $13028 \mathrm{~cm}^{-1}$ (at a frequency $\sim 3350 \mathrm{~cm}^{-1}$ ) and 1.27 respectively. The absorption coefficient, $K_{f m a x}$, for the $\mathrm{SiO}_{2}$ films was evaluated from the absorbance in the range $\sim 3300 \mathrm{~cm}^{-1}$ and thickness, $d$, using the following equation:

$$
K(v)=\frac{2.303}{d} A_{O H}
$$

where $\mathrm{A}_{\mathrm{OH}}$ is the peak intensity of the $\mathrm{O}-\mathrm{H}$ stretching vibration band in the measured absorbance spectrum. The refractive index, $n_{f}$, is taken as 1.457 (typical value for an $\mathrm{SiO}_{2}$ film).
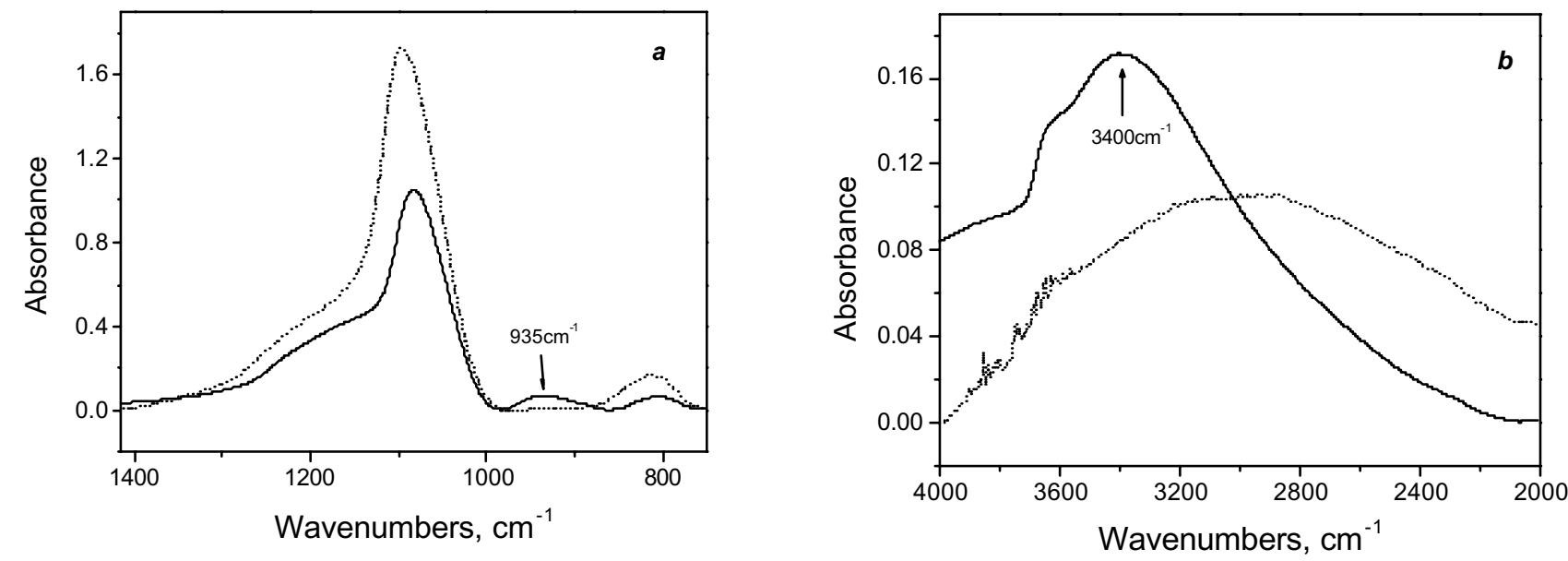

Figure 3. The comparison of FTIR spectra of electron beam evaporated $\mathrm{SiO}_{2}$ (solid line) and thermally grown dioxide (dotted line) in the range of Si-O vibrations $(a)$ and $\mathrm{O}-\mathrm{H}$ vibrations $(b)$.

Prior to calculating the porosity for the evaporated samples, the thickness had to be determined. This is not straightforward since the absorption intensity of the $1080 \mathrm{~cm}^{-1}$ band for evaporated oxides is not the same as that for thermally grown oxides. Therefore, a new absorption coefficient needed to be ascertained for each absorption band in 
the spectrum shown in Fig. 3. This was achieved by analysing the interference fringes from EV1, the $1 \mu \mathrm{m}$ sample. Interference fringes provide a direct way to calculate the thickness rather than from the indirect absorption technique. The calculated thickness from interference fringes for sample EV1 was $1.04 \mu \mathrm{m}$. This value and the absorbance $(A)$ of each band was then substituted into Eqn. (4) to yield new values for $\alpha_{\text {app }}$ which are summarised in Table 1.

$$
A=\log \frac{I_{0}}{I}=0.434 \alpha_{a p p}\left(x-x_{0}\right)
$$

where A is absorbance, $I_{0}$ and $I$ are the incident and transmitted intensities respectively, $\alpha_{\text {app }}$ is the apparent absorption coefficient, $x_{0}$ is the native oxide $(\sim 15 \AA)$ and $x$ is the oxide thickness (see Refs. $[1,2,4]$ for details).

Table 1 Calculated absorption coefficients for 800,935 and $1080 \mathrm{~cm}^{-1}$ bands. The combined intensity of the $800 \mathrm{~cm}^{-1}$ and $935 \mathrm{~cm}^{-1}$ bands may be used with the appropriate $\alpha_{a p p}$.

\begin{tabular}{cc}
\hline BAND & $\alpha_{\mathrm{app}}$ \\
\hline $800 \mathrm{~cm}^{-1}$ & $0.142 \times 10^{4} \mathrm{~cm}^{-1}$ \\
$935 \mathrm{~cm}^{-1}$ & $0.157 \times 10^{4} \mathrm{~cm}^{-1}$ \\
$935 \& 800 \mathrm{~cm}^{-1}$ & $0.299 \times 10^{4} \mathrm{~cm}^{-1}$ \\
$1080 \mathrm{~cm}^{-1}$ & $2.349 \times 10^{4} \mathrm{~cm}^{-1}$ \\
\hline
\end{tabular}

Using these coefficients the thickness, $d$, of each sample could be defined. The values are given in Table 2 . Thickness measurements using ellipsometry are also shown.

Table 2 Sample thickness based on calculated values of $\alpha_{\text {app }}$, \& ellipsometry.

\begin{tabular}{ccc}
\hline SAMPLE & THICKNESS, $d\left(\alpha_{\mathrm{app}}\right)$ & THICKNESS (ELLIPS.) \\
\hline EV1 & $1.04 \mu \mathrm{m}$ & $1.01 \mu \mathrm{m}$ \\
EV2 & $1913 \AA$ & $1960 \AA$ \\
EV3 & $112 \AA$ & $208 \AA$ \\
\hline
\end{tabular}

The porosity can now be calculated from Eqns. (2) and (3) since both the thickness and absorbance intensity at $3400 \mathrm{~cm}^{-}$ ${ }^{1}$ are available. From Table 3 it seems that the thinnest sample, EV3, is the most porous.

Table 3 Calculated porosity for samples EV1, EV2 and EV3.

\begin{tabular}{cc}
\hline SAMPLE & POROSITY, $V$ \\
\hline EV1 & $13 \%$ \\
$\mathrm{EV} 2$ & $11 \%$ \\
$\mathrm{EV} 3$ & $24 \%$ \\
$\mathrm{Thermal} \mathrm{SiO}_{2}$ & $\sim 3 \%$ \\
$\mathrm{Th}^{2}$ & $<3 \%$ \\
\hline
\end{tabular}


This explains the figures given in Table 2 for film thickness. Ellipsometry and IR agree for samples EV1 and EV2, but ellipsometry gives almost double the thickness for EV3. This was due to the high water content in sample EV3, which is almost double that present in samples EV1 and EV2. OH groups present in the pores are negative ions and are not neutral like $\mathrm{H}_{2} \mathrm{O}$. These ions will increase the refractive index and give larger thickness readings when measured with ellipsometry. Care must be taken when analysing the results. This is because FTIR cannot differentiate between surface porosity and bulk porosity.

\subsection{Thickness measurements with IRRAS}

Fig. 4 shows IRRAS spectra for two angles of incidence with $s$-polarisation. The smooth structures between $1500 \mathrm{~cm}^{-1}$ and $3500 \mathrm{~cm}^{-1}$ are known as Fabry-Perot resonances [17] which are useful in the determination of the thickness of the oxide film. Note how the minima of the Fabry-Perot structures shifts to the high frequency side as the angle of incidence increases. The condition for the observation of the minima in the Fabry-Perot interference structure is [17]:

$$
n d=m \frac{\lambda_{\min }}{4}
$$

where $d$ is the film thickness, $m$ is the number of the minimum ( 1 in the case of Fig. 4 ), $\lambda$ is the wavelength (in $\mu m$ ), $n$ is the refractive index of the film (1.462).

Since the IR beam is at an angle of incidence, $\theta$, then the thickness $d$ may be calculated from Eqn. (6):

$$
d=\frac{m \lambda}{4 n \operatorname{Cos} \theta}
$$

The term $\operatorname{Cos} \theta$ is used as a correction factor. Without it, $d$ would be the path length of the IR beam and not the film thickness.

Using Eqn. (6) and the minima read from the spectra, the values of the film thickness given in Table 4 are calculated.

Table 4 Angle of incidence $(\theta)$ and calculated thicknesses.

\begin{tabular}{ccc}
\hline$\theta$ & MINIMUM & THICKNESS \\
\hline $25^{\circ}$ & $2063 \mathrm{~cm}^{-1}$ & $0.92 \mu \mathrm{m}$ \\
$40^{\circ}$ & $2166 \mathrm{~cm}^{-1}$ & $1.03 \mu \mathrm{m}$ \\
\hline
\end{tabular}

The calculations are in good agreement with each other and ellipsometry, which measured the film thickness to be $1.00 \mu \mathrm{m}$.

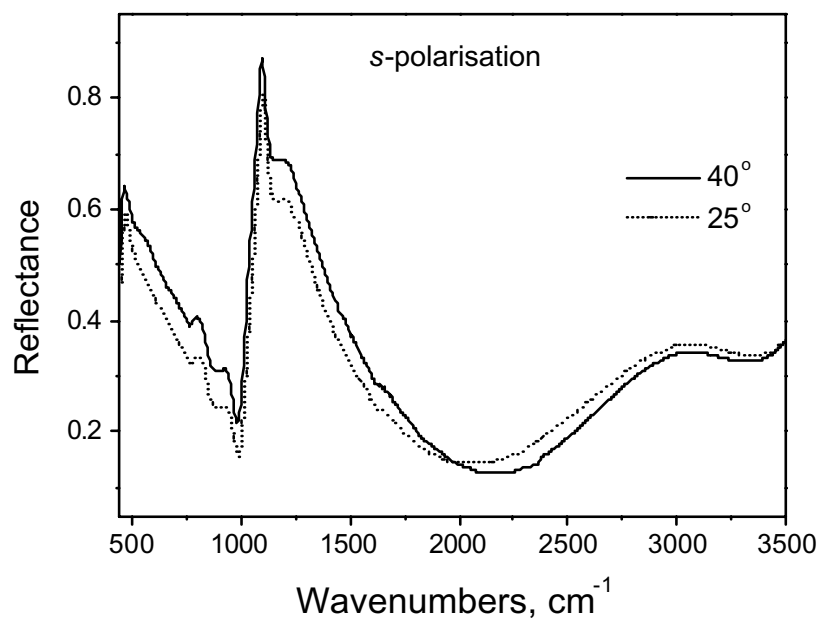

Figure 4. IRRAS spectra of $1 \mu \mathrm{m} \mathrm{SiO}_{2}$ film on silicon for $\theta=25^{\circ}$ (dotted line) and $40^{\circ}$ (solid line) with $s$-polarisation. Note how the minima of the Fabry-Perot structure shifts to the high frequency side as the angle of incidence is increased. 
Interference fringes are observed if the spectrum is collected over a wide enough range and if the oxide film is thick. If the spacing between two fringe maxima or minima is known, then fringes can be used to define the first minimum of the Fabry-Perot resonance. The spectra in Fig. 5 are for $\mathrm{SiO}_{2}$ with $3 \%$ fluorine added. The oxide was deposited onto a silicon substrate. A comparison of film thicknesses as measured with fringes and Fabry-Perot resonance is shown in Table 5.

From Fig. 5 it is clear that the first minimum of the Fabry-Perot resonance is difficult to determine. In this case, the fringe method is used to calculate where the first minimum should be. Eqn. (5) can then be applied as usual. The thicknesses obtained as described above were used for porosity calculations and the results are shown in Table 3.

Table 5 Comparison of interference fringes and Fabry-Perot resonance for film thickness measurements. Results for $3 \%$ and $5 \%$ fluorine doped, and phosphorus doped oxides are given. The angle of incidence was $25^{\circ}$ in all cases.

\begin{tabular}{ccc}
\hline OXIDE DOPING & FRINGES & FABRY-PEROT \\
\hline 3\% fluorine & $1.63 \mu \mathrm{m}$ & $1.54 \mu \mathrm{m}$ \\
$5 \%$ fluorine & $1.65 \mu \mathrm{m}$ & $1.58 \mu \mathrm{m}$ \\
Phosphorus & $0.91 \mu \mathrm{m}$ & $0.82 \mu \mathrm{m}$ \\
\hline
\end{tabular}

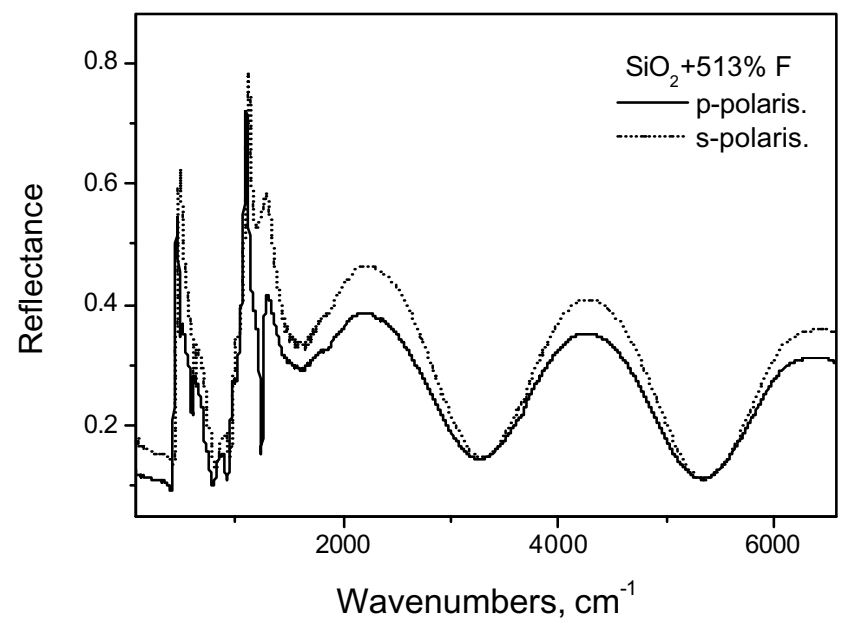

Figure 5. IRRAS spectrum of 5.13 at. \% fluorine doped $\mathrm{SiO}_{2}$ on silicon for $s$ and $p$-polarisations. The film thickness was calculated to be $1.54 \mu \mathrm{m}$ with the FabryPerot resonance.

\subsection{Raman results}

The Raman spectrum of crystalline silicon in a phonon region mainly consists of a narrow peak around $520 \mathrm{~cm}^{-1}$ with a half-width of about $3.5 \mathrm{~cm}^{-1}$ (see Fig. 6). The spectrum arises from scattering by long-wavelength transverse optical phonons [9-11]. This band is very intense, isolated and can be fitted by a single Lorentzian curve shape. Removal of the background baseline followed by a line fit using a Lorentzian function allows three components of the Raman spectrum to be determined viz. intensity, half-width and position. These variations are related to the composition, defect density, and magnitude of stress respectively.

At higher acquisition times (100-300s), a number of additional bands (depending on the Si ingot growth process) become visible in the spectrum of crystalline Si. These bands for Czochralski gown silicon wafers appear at frequencies $\sim 300 \mathrm{~cm}^{-1}$ (2TA -transverse acoustical mode of the Si lattice) and at 605,810 and $1060 \mathrm{~cm}^{-1}$ [23]. The former few bands may appear due to the presence of different defects in the crystalline structure and, in particular, to the presence of oxygen and boron. 
The Raman spectra of silicon dioxide and fluorine doped silicon dioxide looks quite different and consists of a number of vibrational bands which originate from the $\mathrm{SiO}_{2}$ network structure (bands at $\sim 460, \sim 810, \sim 1065$ and $1200 \mathrm{~cm}^{-1}$ ) and from the breathing modes of fourfold and threefold ring defects $\left(490\right.$ and $\left.610 \mathrm{~cm}^{-1}\right)[24,25]$. The position and the intensity of these bands will change with addition of fluorine. As was shown in Ref. [24], the increase in fluorine concentration leads to the increase in the intensities of bands observed at $490 \mathrm{~cm}^{-1}$ and $960 \mathrm{~cm}^{-1}$. At the same time, the addition of fluorine leads to the decrease in the intensities of bands observed at 610,810 and $1060 \mathrm{~cm}^{-1}$ (see Ref. [25]).

Bearing this in mind, we performed the comparison of the Raman spectra obtained from the same positions of the laser spot on the line along the FIB box in two devices (patterned wafers) with normal ("good" device) and abnormal ("bad" device) fluorine concentrations. (FIB box is the square cube cut into the silicon using a focused Gallium ion beam). The results of this comparison are presented in Fig. $6 a-c$ for spectra with the same order number (which corresponds to the same distance from the starting point 0 ) for both devices. As one can see from the spectra shown in Fig. $6 a$, there is no noticeable difference between the Raman spectra for the good and bad devices in the range of distances 0 to $5.9 \mu \mathrm{m}$ (from the $\mathrm{CoSi}-\mathrm{SiO}_{2}+\mathrm{P}$ interface). At the $5.9 \mu \mathrm{m}$ point, a noticeable change in Raman spectrum of the bad device appears at $490 \mathrm{~cm}^{-1}$ (see Fig. $6 \mathrm{~b}$ ), which corresponds to the breathing mode of fourfold ring defects in the $\mathrm{SiO}_{2}$ network and this arises due to the increase of the fluorine concentration. The intensity of this band still increases when we move to the $\sim 7.0 \mu \mathrm{m}$ position and then decreases slightly after moving to the $8.0 \mu \mathrm{m}$ position. In the range 8.1 to $9.0 \mu \mathrm{m}$, the Raman spectra for both devices look quite similar (not shown). However, in the range 9.1 to $10.0 \mu \mathrm{m}$ (Fig. $6 \mathrm{c}$ ) the difference between the Raman spectra for these two devices appears again, but this time the band at $490 \mathrm{~cm}^{-1}$ appears in the spectrum of the good device only.
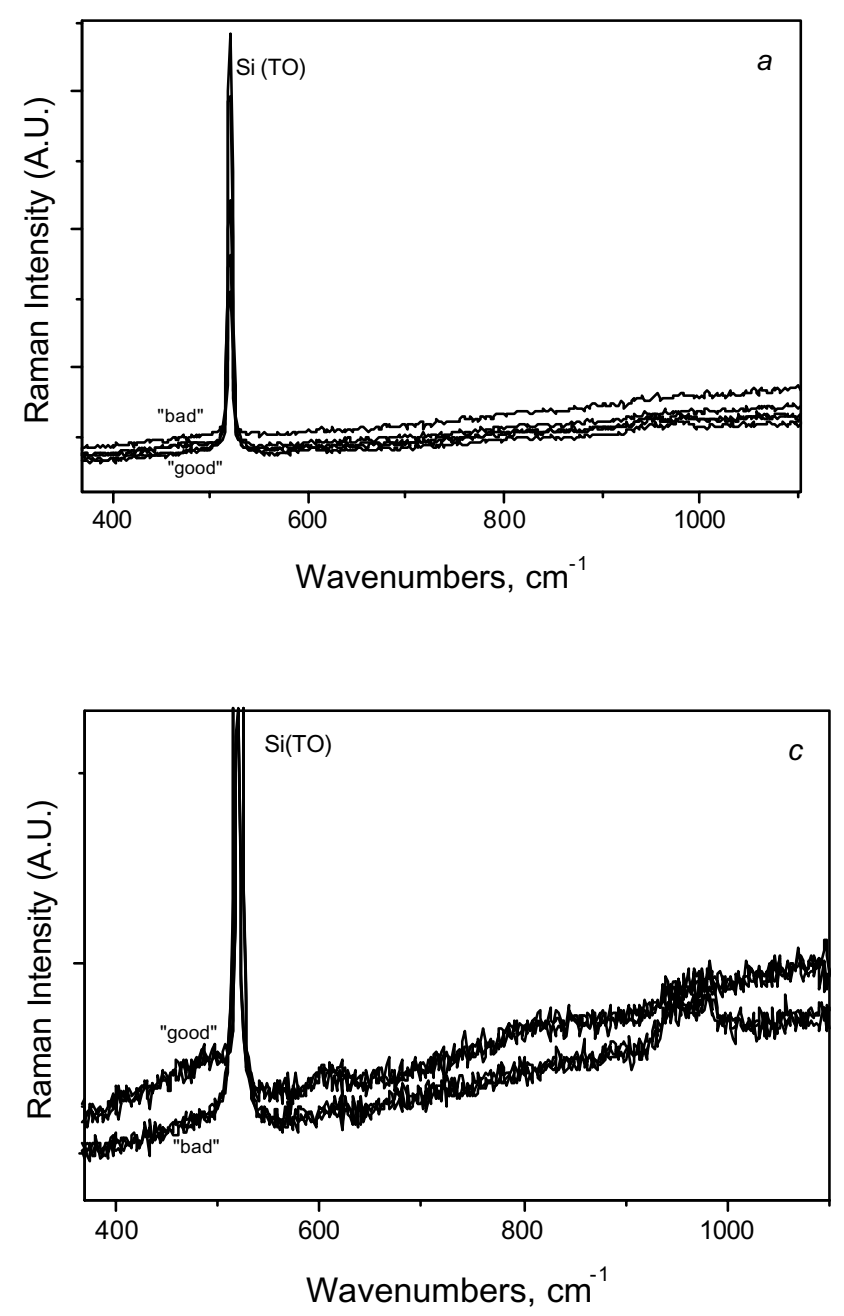

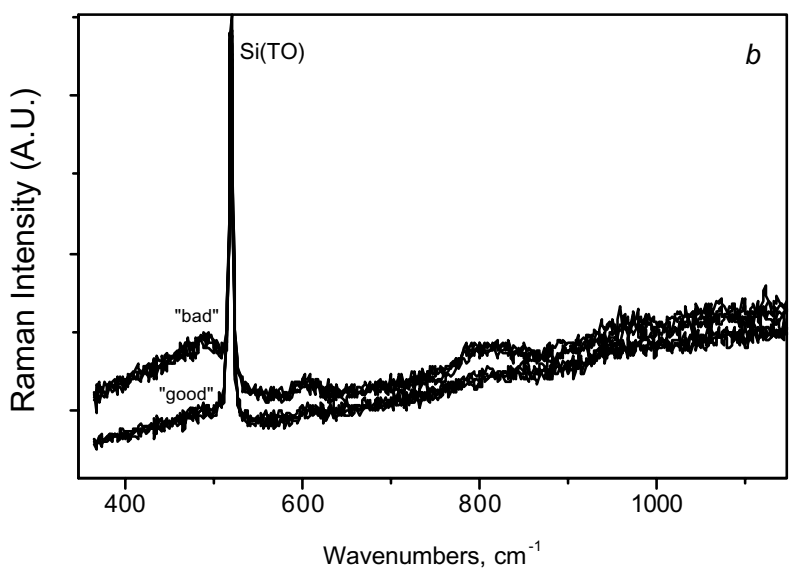

Figure 6. Comparison of Raman spectra collected from the same positions in a FIB box for "bad" and "good" device structures: $a$-at the distance up to 5 $\mu \mathrm{m}$ from the starting point; $b-$ at the distance 5.1-7 $\mu \mathrm{m}$ and $c-$ at the distance 9.1-10 $\mu \mathrm{m}$. (Note that the scale of $\mathrm{Y}$ axis is increased in Fig. $3 c$ in order make a kink around $490 \mathrm{~cm}^{-1}$ more pronounced). 
Based on this observation, we can conclude that in the "bad" device (with respect to the "good" device) the excess of the fluorine concentration is observed along the distance 5.9 to $8.0 \mu \mathrm{m}$ from the CoSi-SiO2+P interface and a deficiency of fluorine concentration is found in the range 9.1 to $10 \mu \mathrm{m}$.

It is difficult to determine the fluorine concentration in a FIB box quantitatively due to the presence of the much stronger Si phonon line closely beside the band at $\sim 490 \mathrm{~cm}^{-1}$, special care should be taken in order to eliminate the influence of this strong band. This can be done by the deposition of a thin Al layer $(\sim 0.1 \mu \mathrm{m}$ thick) between the $\mathrm{Si}$ substrate and $\mathrm{SiO}_{2}+\mathrm{F}$ layers. This $\mathrm{Al}$ layer will eliminate possible scattering from the Si substrate and thus the much stronger Raman signal will be eliminated (or at least substantially suppressed). This will allow proper registration of the band at $490 \mathrm{~cm}^{-1}$.

It should be noted that during this study our attempts to use for this analysis other fluorine bands in the high frequency region (600-1300 $\left.\mathrm{cm}^{-1}\right)$ were felt due to the overlapping of these fluorine bands with the bands belonging to the $\mathrm{Si}$ substrate. The presence of the vibrational bands belonging to the Si substrate in the Raman spectrum taken from inside of the FIB box is due to the diffraction effect at the FIB box edges. Using a long focus 100x objective in the Leica microscope instead of a short focus one (used in present study) can eliminate this effect.

\section{CONCLUSIONS}

The intensity of the absorption bands were used to determine the thickness of doped $\mathrm{SiO}_{2}$ films. The band at $945 \mathrm{~cm}^{-1}$ provided sufficient information for this purpose. Care must be taken not to confuse the fluorine band at $945 \mathrm{~cm}^{-1}$ and the band at $935 \mathrm{~cm}^{-1}$ observed in the spectrum of the evaporated oxide. Careful examination of the spectrum of the evaporated oxide shows the $935 \mathrm{~cm}^{-1}$ and $810 \mathrm{~cm}^{-1}$ bands quite similar in intensity and shape, while the fluorine band at $945 \mathrm{~cm}^{-1}$ tends to be somewhat smaller when compared to the $810 \mathrm{~cm}^{-1}$ band. Investigations of doped oxides show that their structure changes over time. Although the intensity of the $1080 \mathrm{~cm}^{-1}$ and $460 \mathrm{~cm}^{-1}$ bands decreased with time, the $800 \mathrm{~cm}^{-1}$ band did not appear to change. This band, therefore, could be used for film thickness evaluation provided an accurate value for $\alpha_{\text {app }}$ was calculated. The effect was more pronounced for the case of the phosphorus doped sample. Also, the interferences fringes remained constant for each sample, enabling the accurate determination of the oxide thickness.

The porosity of $\mathrm{SiO}_{2}$ films was calculated. Care must be taken when analysing the results since FTIR cannot differentiate between surface porosity and bulk porosity. This is a disadvantage of infrared spectroscopy insofar as it is not possible to discern whether porosity is constant throughout the bulk material or localis ed at the film surface. Interference fringes only appear in the spectrum if the oxide is thick enough. Transmission infrared measurements also benefit from a thicker oxide. For this reason, it was preferable to measure the thickness of the thin oxide samples by IRRAS. These thickness calculations were performed by using the Fabry-Perot resonance structures that appeared in the spectrum regardless of film thickness. The excess and deficiency of the fluorine concentration have been determined using Raman Ine-mapping experiments in a FIB box of devices with normal $\left(3.18\right.$ at. \% $\mathrm{F}$ in $\left.\mathrm{SiO}_{2}\right)$ and abnormal fluorine concentrations. It has been found that at higher fluorine concentrations the intensity of the band at $490 \mathrm{~cm}^{-1}$ is increases substantially.

\section{ACKNOWLEGMENTS}

CM wishes to thank Intel, Ireland for financial support of this work through the Postgraduate Studentship Programme.

\section{REFERENCES}

1. I.W. Boyd and J.I.B. Wilson, "A study of thin silicon dioxide films using infrared absorption techniques", J.Appl.Phys. 53, pp. 4166-4172, 1982.

2. P.G. Pai, S.S. Chao, and Y. Takagi, "Infrared spectroscopic study of $\mathrm{SiO}_{\mathrm{x}}$ films produced by plasma enhanced chemical vapor deposition", J.Vac.Sci.Technol. A4, pp. 689-694, 1986. 
3. W.A. Pliskin, "Use of infrared spectroscopy for the characterisation of dielectric films on silicon", in Semiconductor silicon, ed. By H.R. Huff and R.R. Burgess, Electrochemical Society, Pennington, NJ, 1973, pp. 506-529.

4. G. Lukovsky, M.J. Mantini, J.K. Srivastava and E.A. Irene, "Low-temperature growth of silicon dioxide films: a study of chemical bonding by ellipsometry and infrared spectroscopy”, J.Vac.Sci.Technol. B5, pp. 530-537, 1987.

5. R. A. B. Devine, "Structural nature of the $\mathrm{Si} / \mathrm{SiO} / \mathrm{sub} 2 /$ interface through infrared spectroscopy," Appl. Phys. Lett. 68, pp. 3108-3110, 1996.

6. J.E. Olsen and F. Shimura, "Infrared spectroscopy of thin silicon dioxide on silicon", Appl.Phys.Lett. 53, pp. 19341936, 1988.

7. C.T. Kirk, Phys. Rev. B38, pp. 1255-1273, 1988.

8. I.I. Shaganov, T.S. Perova, R.A. Moore and K. Berwick, Spectroscopic characterisation of $\mathrm{SiO}_{\text {and }} \mathrm{SiO}_{2} \mathrm{solid}$ films: Assignment and local field influence, J.Material Science: Materials in Electronics, 12, pp. 351-355, 2001.

9. M.J. Pelletier, Analytical applications of Raman spectroscopy, 1999.

10. G.Turrell, J. Corset, Raman microscopy, Academic Press, 1996.

11. I. De Wolf, "Micro-Raman spectroscopy to study local mechanical stress in silicon integrated circuits," Semicond. Sci.Technol. 11, pp. 139-154, 1996.

12. K. Ajito, J.P.H. Sukamoto, L.A. Nagahara, K. Hashimoto, A. Fujishima, "Strain imaging analysis of Si using Raman microscopy," J.Vac.Sci.Technol. A 13, pp. 1234-1238,1995.

13. S. Webster, D.N. Batchelder, D.A. Smith, 'Submicron resolution measurement of stress in silicon by near-field Raman spectroscopy," Appl.Phys.Lett. 72, pp.1478-1480, 1998.

14. M Nolan, T.S. Perova, R.A. Moore, C.J. Moore, K. Berwick and H.S. Gamble, "Micro-Raman study of stress distribution generated in silicon during proximity rapid thermal diffusion”, Mater.Sci. \& Engineering, B73, pp. 168-172, 1999.

15. O.P. Konovalova, O.Yu. Rysakova and I.I. Shaganov, "The determination of the optical constants thin films evaporated onto the metal in vacuum from IR reflection", Sov.J.Opt.Technol. 55, pp. 402-404, 1988.

16. K.B. Kent, A. William, A. Schmidt and E. Butler, In situ reflection absorption spectroscopic characterisation of plasma enhanced chemical vapor deposited $\mathrm{SiO}_{2}$ films, J. Appl.Phys., 64, pp.4704-4710, 1988.

17. P. Grosse, B. Harbecke, B. Heinz, R. Meyer, M. Offenberg, "Infrared spectroscopy of oxide layers on technical Si wafers", Appl.Phys. A39, pp. 257-268, 1986.

18. J.E. Franke, T.M. Niemczyk, and D. Haaland, "Infrared spectroscopic techniques for quantitative characterization of dielectric thin films on silicon wafers", Spectrochim. Acta, 50A, pp. 1687-1723 (1994).

19. T.S. Perova, C. Beitia, M. Nolan, R.A. Moore, J. McGilp and H. Gamble, "Borosilicate glass as a spin-on dopant source: FTIR and spectroscopic ellipsometry investigations", (submitted for publication).

20. L.D. Madsen, A.C. de Wilton and J.S. Mercier, "Examination of the stability of borophosphosilicate glass films", Chemtronics, 5, pp. 35-42 (1991).

21. A.F. Perveev, G.A. Muranova, \& V.M. Zolotarev, Sov. Solid State Phys., 14, pp. 2510, (1972).

22. I.I. Shaganov, "Manifestation of local field effects in the properties of optical materials and coatings", Sov. J, Opt. Technol., 59, pp. 1-11, 1992.

23. Y. Gogotsi, C. Baek and F. Kirsch, "Raman microspectroscopy study of processing-induced phase transformations and residual stress in silicon,"Semicond. Sci. Technol. 14 pp.936-944, 1999.

24. S.W. Lim, Y. Shimogaki, Y. Nakano, K. Tada and H. Komiyama, "Changes in orientational polarization and structure of silicon dioxide film by fluorine addition," J. Electrochem. Soc. 146, pp. 4196-4202, 1999

25. M. Yoshikawa, K. Iwagami, N. Morita, T. Matsunobe and H. Ishida, "Characterization of fluorine-doped silicon dioxide films by Raman spectroscopy,” Thin Solid Films 310, pp.1167-170, 1997. 